\title{
ПОТЕНЦИАЛ ГОСУДАРСТВЕННО-ЧАСТНОГО И МУНИЦИПАЛЬНО-ЧАСТНОГО ПАРТНЁРСТВ В СИСТЕМЕ ФИНАНСИРОВАНИЯ ПРЕДПРИЯТИЙ АПК"
}

\author{
(c) 2018 Бондаренко Татьяна Григорьевна \\ кандидат экономических наук, доцент кафедры финансового менеджмента \\ Российский экономический университет имени Г.В. Плеханова \\ 117997, г. Москва, Стремянный пер., 36 \\ (C) 2018 Жданова Ольга Александровна \\ доцент кафедры финансового менеджмента \\ Российский экономический университет имени Г.В. Плеханова \\ 117997, г. Москва, Стремянный пер., 36 \\ (c) 2018 Горяинова Людмила Владимировна \\ кандидат экономических наук, доцент кафедры экономической теории \\ Российский экономический университет имени Г.В. Плеханова \\ 117997, г. Москва, Стремянный пер., 36 \\ E-mail: lvgoryainova@mail.ru
}

Обосновывается возможность финансирования предприятий АПК с использованием механизма ГЧП, что актуально в условиях недостатка бюджетных средств. Показано, что для активизации партнёрских отношений, необходимо развитие ГЧП на основе использования критериев соответствия объектов АПК, по которым возможно заключение соглашений. Обоснованы перспективы ГЧП в направлении развития интеграции предприятий по производству сельхозпродукции.

Ключевые слова: государственно-частное партнёрство, агропромышленный комплекс, концессия, частная инициатива, публичная инициатива, интеграция, компетенции.

Значение сельского хозяйства как вида деятельности определяется его местом в системе общественного воспроизводства, тем, что отрасль создаёт условия стабильности воспроизводственного процесса и продовольственной безопасности, являющейся составным элементом экономической безопасности страны. Академик Л.И. Абалкин определял экономическую безопасность как «совокупность условий и факторов, обеспечивающих независимость национальной экономики, ее стабильность и устойчивость, способность к постоянному обновлению и совершенствованию» [1, С. 5].

Сельское хозяйство является отраслью, обладающей сильным мультипликативным эффектом, что доказывается значительной долей промежуточного продукта в валовом выпуске отрасли - 50,0\% по данным за 2014 г. [2, С. 35].

Вся история сельского хозяйства - это история повышения производительности труда и технологического прогресса. Однако эти позитивные изменения не приносили устойчивости аграрному сектору, вызывая в нём нестабильность цен и сокращение доходов фермеров [3,
С. 324]. Такие последствия прогресса сделали необходимым сопричастность государства к процессу воспроизводства в сельском хозяйстве и организацию системы государственных субсидий фермерским хозяйствам.

В настоящее время субсидии сельскому хозяйству в России существуют как компенсация средств по нескольким направлениям: за удобрения; на приобретение сельскохозяйственных животных; за строительство производственных объектов; для модернизации в хозяйстве; для приобретения земли, подведения коммуникационных сетей, строительства сельскохозяйственных объектов; по платежам за лизинг [4].

В условиях недостатка бюджетных средств практически значимой задачей является поиск механизмов активного привлечения частных инвестиций в сельское хозяйство. Во взаимоотношениях субъектов аграрного сектора и государства определены новые подходы: наряду с субсидированием отрасли получают распространение меры поддержки путём объединения усилий государства и предпринимателей в виде практики государственно-частного партнерства

"Работа выполнена при финансовой поддержке РЭУ имени Г.В. Плеханова 
(ГЧП).

ГЧП-механизм развития общественной инфраструктуры предполагает взаимодействие государства и предпринимателей, при котором частный партнёр участвует не только в проектировании, финансировании, строительстве объекта, но и в его последующей эксплуатации в интересах публичного партнёра.

В соответствии с макроэкономической теорией, если государственные инвестиции растут, то частные - сокращаются. Тем не менее, сложно найти доказательства вытеснений инвестиций в частном секторе ГЧП - проектами, что позволяет сделать вывод о том, что ГЧП выступает дополнением к другим формам государственного инвестирования, а не заменяет их [5, С.41]. Участие государства формирует необходимый уровень доверия и снимает регуляторные ограничения при реализации проектов.

По числу реализованных ГЧП - проектов в мировой практике сельское хозяйство не относится к числу отраслей - лидеров. Неплохой опыт накоплен в США, Индонезии, Пакистане в области растениеводства; в Дании, Нидерландах, Таиланде - в животноводстве; в Исландии, Филиппинах - в рыболовстве; в Армении, Филиппинах -в проектах по строительству и эксплуатации ирригационных систем [6, С. 10-11]. В России этого опыта пока немного, поскольку законодательство по регулированию процесса реконструкции и создания новых объектов АПК на основе партнёрства государства и предпринимателей начало формироваться только в 2017-2018годах, однако перспективы ГЧП в этой сфере деятельности велики и обусловлены трендами развития мировой экономики, одним из которых является конкуренция цепочек создания стоимости и интеграции предприятий по производству сельхозпродукции. Государство может выступить в этом случае базисом в формировании межфирменной кооперации и интеграции в АПК [7, С. 20].

Общая нормативно-правовая база ГЧП в РФ в настоящее время включает федеральный закон от 13.07.2015 № 224-Ф3 «О государственно-частном партнерстве, муниципально-частном партнерстве в Российской Федерации и внесении изменений в отдельные законодательные акты Российской Федерации» и федеральный закон от 21.07.2005 № 115-Ф3 «О концессионных соглашениях». Критериями ГЧП в соответствии с законодательством выступают: долгосрочный характер соглашения, распределение рисков, полное или частичное финансирование проекта частным партнёром. Критериям ГЧП соответствует и концессионное соглашение, поэтому его рассматривают как организационно- правовую форму ГЧП, что обуславливает существование двух форм ГЧП: соглашения о ГЧП (МЧП) и концессионного соглашения. Законодательное выделение этих критериев не позволяет относить к ГЧП такие формы государственной поддержки как: субсидирование, кредитование, льготное налогообложение, государственный заказ, контракт жизненного цикла.

Российское законодательство содержит указание на возможность выбора варианта организационно-правовой формы для реализации инвестиционного проекта с государственным участием, совершенствуется правовая база в этой части, ведется поиск новаций в направлениях взаимодействия государства и предпринимателей. Приобретает актуальность решение вопросов формирования методической базы выбора правового механизма для проектов с различными характеристиками, создания финансовой модели с помощью которой оцениваются финансовая и сравнительная эффективность проекта.

Проблемы выбора оптимальной формы реализации проектов имеют особую значимость для субъектов РФ и муниципалитетов, поскольку на них возложены функции по осуществлению аграрной политики и отмечается низкий уровень компетенций исполнителей этих работ. В субъектах РФ существуют собственные законы о ГЧП, положения которых также необходимо учитывать при структурировании проекта.

Федеральное законодательство содержит указание на то, что возможна процедура частной инициативы при разработке проекта, в процессе которой частный партнёр должен представить публичному партнёру банковскую гарантию на выдачу кредита на сумму не менее 5\% от суммы финансирования проекта. Преимуществом частной инициативы для государства представляется возможность сократить время отбора частного партнёра, переложить расходы на разработку проекта на его инициатора. Для частного партнёра привлекательным выступает то, что он на правах инициатора проекта может добиться выгодных условий реализации проекта.

Право частной собственности на объект соглашения по ФЗ-115 может возникнуть только 
у публичного партнёра. Частный партнёр может выкупить объект, если он включен в программу приватизации после завершения срока действия соглашения. По Ф3 - 224 право частной собственности возникает у частного партнёра. Объект должен быть передан в собственность публичного партнера в случае, если его капитальные вложения превышают 50\% от общей стоимости создания объекта.

Особенности объектов агропромышленного комплекса потребовали принятия Постановления Правительства РФ от 29.12.2017 N1686, определившего критерии, которым должны соответствовать сельскохозяйственные объекты для заключения концессионного соглашения или соглашения о ГЧП (либо МЧП) [8]. В апреле 2018года был подготовлен проект постановления об утверждении перечня объектов сельского хозяйства, по которым может быть заключено соглашение ГЧП, но 30.07.2018 президентом был подписан закон, уточняющий положения Ф3 -115 и Ф3 -224 и исключающий указание на необходимость утверждения перечня объектов в сфере сельского хозяйства. Поправками в законодательство предусмотрено, что для отнесения к объектам ГЧП и концессии объектов производства, первичной или последующей переработки, хранения сельскохозяйственной продукции, достаточно их соответствия критериям, установленным Правительством РФ [9].

Данная норма, по мнению специалистов, должна была расширить доступ сельскохозяйственных производителей к механизмам ГЧП, поскольку региональные власти и муниципалитеты не шли на заключение таких соглашений без утвержденного Перечня объектов, что создавало дополнительные риски в процессе подготовки проектов. В настоящее время в сфере сельского хозяйства реализуются следующие проекты с использованием механизма ГЧП (табл.).

Из 10 реализуемых проектов в четырёх случаях формой реализации ГЧП стала частная инициатива, в четырёх случаях - публичная инициатива, два проекта реализуются по концессионным соглашениям.

Отсутствие законодательно закреплённых объектов ГЧП в АПК, а установление лишь критериев этих объектов делает практически значимым выявление потенциальных направлений деятельности агропромышленного комплекса и видов его объектов, для которых необходимо и возможно применение форм ГЧП. Для обосно- вания этих форм выделим те задачи, решение которых требует участия государства в концессионных соглашениях и соглашениях ГЧП.

1. Обеспечение гарантированного спроса со стороны государства для более полного использования мощностей объекта и снижения срока его окупаемости может быть востребовано при создании селекционно-семеноводческих центров в растениеводстве, селекционно-генетических центров в животноводстве и рыбоводстве. В данном случае, если государство осуществляет софинансирование реконструкции объекта и предоставляет гарантии по обеспечению закупок продукции, возможно использование положений Ф3-115, а если предполагается переход права собственности, то используется Ф3-224.

2. Представление ГЧП - проектов в качестве альтернативы приватизации коммерчески непривлекательных объектов и обеспечение в процессе реконструкции перехода прав собственности к инвестору проекта. В 2017-2019 гг. планируется приватизация 52-х объектов АПК, находящихся в государственной собственности, среди которых: учебно-опытные хозяйства, племенные заводы, семеноводческие станции, кукурузокалибровочный завод, льносеменоводческая станция [11, С. 16-20] и др. Для данной модели, предусматривающей переход прав собственности на объект соглашения частному партнеру, в рамках действующего законодательства возможно применение только соглашения о ГЧП / МЧП (ФЗ-224). В результате приватизации практически все интересы правительства в использовании актива передаются частному партнёру. Приватизированный актив отличается от частного коммерческого предприятия тем, что правительство обычно сохраняет косвенную форму контроля или механизм регулирования в форме лицензии для предоставления публичной услуги. Возможно софинансирование затрат на реконструкцию объекта и гарантии на операционной стадии со стороны публичного партнёра при условии, что участие публичного партнера в реализации должно быть менее $50 \%$.

3. Строительство нового объекта для индивидуального использования производителем или поставщиком возможно в случае животноводческого комплекса мясного и молочного направлений, тепличного комплекса. Если предусматривается переход прав собственности на объект соглашения частному партнеру, возмож- 
Таблица Инвестиционные проекты в АПК, реализуемые с использованием механизма ГЧП и МЧП [10]

\begin{tabular}{|c|c|c|c|c|c|c|}
\hline № & $\begin{array}{c}\text { Инвестиционный } \\
\text { проект в сельскохозяй- } \\
\text { ственной сфере }\end{array}$ & Субъект РФ & $\begin{array}{c}\text { Форма } \\
\text { реализации } \\
\text { ГЧП }\end{array}$ & $\begin{array}{c}\text { Публичный } \\
\text { партнёр }\end{array}$ & $\begin{array}{l}\text { Частный } \\
\text { партнёр }\end{array}$ & $\begin{array}{c}\text { Объём } \\
\text { финанси- } \\
\text { рования } \\
\text { тыс. руб. }\end{array}$ \\
\hline 1. & $\begin{array}{l}\text { «Строительство те- } \\
\text { пличного комплекса } \\
\text { с использованием } \\
\text { геотермальных источ- } \\
\text { ников энергии» }\end{array}$ & $\begin{array}{l}\text { Республика } \\
\text { Дагестан / СКФО }\end{array}$ & $\begin{array}{l}\text { Публичная } \\
\text { инициатива }\end{array}$ & $\begin{array}{l}\text { Корпорация } \\
\text { развития Респу- } \\
\text { блики Дагестан }\end{array}$ & $\begin{array}{l}\text { ООО «Югагро- } \\
\text { холдинг» }\end{array}$ & $\begin{array}{l}556200 \\
\text { тыс. руб. }\end{array}$ \\
\hline 2. & $\begin{array}{l}\text { «Строительство те- } \\
\text { пличного комплекса по } \\
\text { производству овощных } \\
\text { культур площадью } 20 \\
\text { га» }\end{array}$ & $\begin{array}{l}\text { Ставропольский } \\
\text { край / СКФО }\end{array}$ & $\begin{array}{l}\text { Частная } \\
\text { инициатива }\end{array}$ & $\begin{array}{l}\text { АО «Агентство } \\
\text { инвестицион- } \\
\text { ного развития» }\end{array}$ & $\begin{array}{l}\text { ООО Теплич- } \\
\text { ный Комплекс } \\
\text { «ЭКПРОДУК» }\end{array}$ & $\begin{array}{l}1250000 \\
\text { тыс. руб. }\end{array}$ \\
\hline 3. & $\begin{array}{l}\text { «Создание науч- } \\
\text { но-производственного } \\
\text { семенного кластера по } \\
\text { выращиванию и про- } \\
\text { изводству семенного } \\
\text { материала» }\end{array}$ & $\begin{array}{l}\text { Ставропольский } \\
\text { край / СКФО }\end{array}$ & $\begin{array}{l}\text { Частная } \\
\text { инициатива }\end{array}$ & $\begin{array}{l}\text { АО «Агентство } \\
\text { инвестицион- } \\
\text { ного развития» }\end{array}$ & ООО «Агросид» & $\begin{array}{l}600000 \\
\text { тыс. руб. }\end{array}$ \\
\hline 4. & $\begin{array}{l}\text { Строительство те- } \\
\text { пличного комплекса } \\
\text { «Новочебоксарский» } \\
\text { площадью } 22 \text { га }\end{array}$ & $\begin{array}{l}\text { Чувашская } \\
\text { Республика / } \\
\text { ПФО }\end{array}$ & $\begin{array}{l}\text { Концессион- } \\
\text { ное соглаше- } \\
\text { ние (115-ФЗ) }\end{array}$ & $\begin{array}{l}\text { АУ «Фонд раз- } \\
\text { вития промыш- } \\
\text { ленности и ин- } \\
\text { вестиционной } \\
\text { деятельности» }\end{array}$ & $\begin{array}{l}\text { ООО ТК «Ново- } \\
\text { чебоксарский» }\end{array}$ & $\begin{array}{l}6007000 \\
\text { тыс. руб. }\end{array}$ \\
\hline 5. & $\begin{array}{l}\text { Строительство те- } \\
\text { пличного комплекса } \\
\text { ООО «Агромир» } \\
\end{array}$ & $\begin{array}{l}\text { Республика } \\
\text { Дагестан / СКФО }\end{array}$ & $\begin{array}{l}\text { Публичная } \\
\text { инициатива }\end{array}$ & \begin{tabular}{|l} 
Корпорация \\
развития Респу- \\
блики Дагестан \\
\end{tabular} & ООО «Агромир» & $\begin{array}{l}385047 \\
\text { тыс. руб. }\end{array}$ \\
\hline 6. & $\begin{array}{l}\text { Животноводческо-рас- } \\
\text { тениеводческий ком- } \\
\text { плекс в Борском районе }\end{array}$ & $\begin{array}{l}\text { Самарская } \\
\text { область / ПФО }\end{array}$ & $\begin{array}{l}\text { Публичная } \\
\text { инициатива }\end{array}$ & $\begin{array}{l}\text { ОАО «Корпора- } \\
\text { ция развития } \\
\text { Самарской } \\
\text { области» }\end{array}$ & $\begin{array}{l}\text { ООО «ОП СХП } \\
\text { «Покровское» }\end{array}$ & $\begin{array}{l}3476000 \\
\text { тыс. руб. }\end{array}$ \\
\hline 7. & $\begin{array}{l}\text { Строительство ком- } \\
\text { плекса по производству } \\
\text { и переработке мяса } \\
\text { птицы в Самарской } \\
\text { области } \\
\end{array}$ & $\begin{array}{l}\text { Самарская } \\
\text { область / ПФО }\end{array}$ & $\begin{array}{l}\text { Публичная } \\
\text { инициатива }\end{array}$ & $\begin{array}{l}\text { ОАО «Корпора- } \\
\text { ция развития } \\
\text { Самарской } \\
\text { области» }\end{array}$ & $\begin{array}{l}\text { ОоО «Европей- } \\
\text { ские биологи- } \\
\text { ческие техноло- } \\
\text { гии» }\end{array}$ & $\begin{array}{l}17700000 \\
\text { тыс. руб. }\end{array}$ \\
\hline 8. & $\begin{array}{l}\text { Строительство мясо- } \\
\text { хладобойни }\end{array}$ & $\begin{array}{l}\text { Саратовская } \\
\text { область / ПФО }\end{array}$ & $\begin{array}{l}\text { Частная } \\
\text { инициатива }\end{array}$ & $\begin{array}{l}\text { Администрация } \\
\text { Энгельсского } \\
\text { муниципально- } \\
\text { го района }\end{array}$ & \begin{tabular}{|l|} 
УК «КоПИТА- \\
НИЯ» (ООО \\
«Свиноком- \\
плекс «Хвалын- \\
ский») \\
\end{tabular} & $\begin{array}{l}500000 \\
\text { тыс. руб. }\end{array}$ \\
\hline 9. & $\begin{array}{l}\text { Строительство птице- } \\
\text { комплекса по произ- } \\
\text { водству и переработке } \\
\text { мяса индейки } \\
\end{array}$ & $\begin{array}{l}\text { Республика } \\
\text { Ингушетия / } \\
\text { СКФО }\end{array}$ & $\begin{array}{l}\text { Частная } \\
\text { инициатива }\end{array}$ & $\begin{array}{l}\text { Корпорация } \\
\text { развития Респу- } \\
\text { блики Ингуше- } \\
\text { тия } \\
\end{array}$ & $\begin{array}{l}\text { ООО «Пти- } \\
\text { цекомплекс } \\
\text { «Южный» }\end{array}$ & $\begin{array}{l}3843 \\
\text { тыс. руб. }\end{array}$ \\
\hline 10. & $\begin{array}{l}\text { Реконструкция объекта: } \\
\text { «Убойный пункт оленей } \\
\text { производительностью } \\
200 \text { голов в смену» }\end{array}$ & $\begin{array}{l}\text { Ямало-Ненецкий } \\
\text { автономный } \\
\text { округ / УФО }\end{array}$ & $\begin{array}{l}\text { Концессион- } \\
\text { ное соглаше- } \\
\text { ние (115-ФЗ) }\end{array}$ & $\begin{array}{l}\text { Администрация } \\
\text { муниципально- } \\
\text { го образования } \\
\text { Надымского } \\
\text { района }\end{array}$ & $\begin{array}{l}\text { Общество } \\
\text { с ограниченной } \\
\text { ответствен- } \\
\text { ностью «ВОЗ- } \\
\text { РОЖДЕНИЕ» }\end{array}$ & $\begin{array}{l}5405 \\
\text { тыс. руб. }\end{array}$ \\
\hline
\end{tabular}


но применение только соглашения о ГЧП / МЧП (Ф3-224). Применение концессионного соглашения целесообразно в том случае, если публичная сторона рассчитывает сохранить право собственности на объект соглашения или вложить в проект более 50\% от общего объема затрат, что является альтернативой реализации инвестиционного проекта с использованием аренды.

4. Создание крупных объектов, используемых многими производителями и поставщиками, предполагает строительство элеваторов, овощехранилищ, плодохранилищ, агро- и производственно-логистических, оптово-распределительных центров, агропромышленных парков, объектов пищевой и перерабатывающей промышленности. Для данной модели целесообразны нормы концессионного законодательства (Ф3-115). Наибольшее распространение моде- ли ГЧП могут получить на перерабатывающих предприятиях, отличительной чертой которых является то, что процессы, лежащие в их основе и результаты их использования, легко поддаются измерению.

Выявление групп объектов АПК, для которых возможно финансирование на основе соглашений о ГЧП (МЧП) и концессионных соглашений и включение этих объектов в законодательство, по мнению авторов, будет способствовать расширению доступа сельхозпроизводителей к ГЧП-механизмам. Распространению практики ГЧП (МЧП) для финансирования предприятий АПК окажет законодательное закрепление формализованной модели выбора формы соглашения и финансовая модель определения финансовой, сравнительной эффективности проекта на прединвестиционной фазе.

\section{Библиографический список}

1. Абалкин Л.И. Экономическая безопасность России: угрозы и их отражение // Вопросы экономики. 1994. № 12. C. 5 .

2. Зинченко А. П. Проблемы воспроизводства в сельском хозяйстве России //Проблемы прогнозирования. 2017. № 2. С. 35 .

3. Вершинина А.А., Горяинова Л.В., Данилина Я.В., Максимова Т.П., Марыганова Е.А., Назарова Е.В. Экономическая теория: учебник для бакалавров // под ред. В.Ф. Максимовой. Москва. С. 324. (Сер. 58 Бакалавр. Академический курс)

4. Сайт Льготы всем [Электронный ресурс] URL: http://goty-vsem.ru/subsidii/grant-na-razvitie-selskogohozyajstvu-nachinayushhemu-fermeru.html (дата обращения 16.09.2018)

5. ̆ескомб Э.Р. Государственно - частное партнёрство: Основные принципы финансирования/ Э.Р. Йескомб. Пер.с.англ. Альпина Паблишер. Москва. 2015. С. 41.

6. Кочеткова С.В. Реализация проектов ГЧП в аграрной сфере: европейский опыт//Контентус. 2017. C. 9-20.

7. Максимова Т.П., Бондаренко Н.Е. Концептуальные основы межфирменной кооперации и интеграционных процессов в системе АПК Российской Федерации //Вестник Российского экономического университета имени Г.В. Плеханова .2017. № 4. С. 13-22.

8. Постановление Правительства РФ от 29.12.2017 N1686 «Об утверждении критериев отнесения объектов производства, первичной и (или) последующей (промышленной) переработки, хранения сельскохозяйственной продукции к объектам концессионного соглашения, соглашения о государственно-частном партнерстве либо муниципально-частном партнерстве» [Электронный ресурс] Доступ из справ.-правовой системы «Консультант Плюс».

9. Федеральный закон РФ от 29.07.2018, № 261-ФЗ О внесении изменений в статью 4 Федерального закона «О концессионных соглашениях» и статью 7 Федерального закона «О государственно-частном партнерстве, муниципально-частном партнерстве в Российской Федерации и внесении изменений в отдельные законодательные акты Российской Федерации» [Электронный ресурс] Доступ из справ.-правовой системы «КонсультантПлюс».

10. Платформа поддержки инфраструктурных проектов// База проектов [Электронный ресурс] / Сайт РОСИНФPA URL: http://www.pppi.ru/projects (дата обращения 15.09.2018)

11. Прогнозный план (программа) приватизации федерального имущества и основные направления приватизации федерального имущества на 2017-2019 гг.С.16-20 [Электронный ресурс] /Сайт Федерального агентства по управлению государственным имуществом. URL: https:/www.rosim.ru/documents/306545. (дата обращения 18.09.2018). 